\title{
TERTIARY PHYSICO-CHEMICAL TREATMENT OF SECONDARY EFFLUENT FROM THE CHANIA MUNICIPAL WASTEWATER TREATMENT PLANT
}

\author{
E. TASSOULA ${ }^{1}$ \\ E. DIAMADOPOULOS ${ }^{2, *}$ \\ C. VLACHOS ${ }^{2}$
}

Received: 15/09/06

Accepted: 15/01/07

\author{
${ }^{1}$ Department of Civil Engineering \\ Aristotle University of Thessaloniki, Thessaloniki, Greece \\ ${ }^{2}$ Department of Environmental Engineering \\ Technical University of Crete, 73100 Chania, Greece
}

*to whom all correspondence should be addressed: e-mail: diamad@dssl.tuc.gr

\begin{abstract}
The present study investigated tertiary physico-chemical treatment of the secondary effluent from the Chania municipal Wastewater Treatment Plant (WTP). Laboratory experiments were carried out with the aim of studying coagulation efficiency regarding reduction of turbidity, soluble COD and phosphorus both in a conventional Coagulation-Settling treatment scheme, as well as by means of Contact Filtration. The results showed that high doses of coagulants $\left(0,5 \mathrm{mmol} \mathrm{Me} \mathrm{Me}^{+3} \mathrm{I}^{-1}\right.$ or higher) are required to achieve significant removals of turbidity after settling. At these high doses, soluble COD can be removed by about $50 \%$, while soluble Phosphorus by $80-95 \%$. Ferric Chloride demonstrated slightly better removal ability as compared to Alum. The Chania WTP effluent was also treated by Contact Filtration, using a very low dose of coagulants, $0,1 \mathrm{mmol} \mathrm{Me} \mathrm{M}^{+1}$. Turbidity was removed by around $50 \%$, while at this low coagulant dose removals of COD and Phosphorus were insignificant. Filtration was effective in the first $35 \mathrm{~cm}$ of the filter bed. No significant differences were observed between the coagulants Alum and $\mathrm{FeCl}_{3}$ in the elimination of turbidity. Nevertheless, with the use of Alum a smaller filter headloss was observed, during the first two hours of continuous filtration, in comparison with the use of $\mathrm{FeCl}_{3}$ (nearly double). No difference was observed between the headloss developed at a filter depth of $5 \mathrm{~cm}$ as compared to that developed at a depth of $70 \mathrm{~cm}$. This indicates that the headloss increase was due to the accumulation of suspended and colloidal solids within the first layers of the sand filter.
\end{abstract}

KEYWORDS: Coagulation, Contact filtration, Secondary effluent, Wastewater reclamation

\section{INTRODUCTION}

Reclamation and reuse of effluents from municipal wastewater treatment plants (WTP) is becoming a matter of great importance in the field of water resources management. Such effluents are now considered as available and economical resources for a variety of applications [1, 2]. The term "wastewater reclamation" refers to appropriate treatment by which wastewater is rendered suitable for re-use (agricultural and landscape irrigation, industrial water supply, groundwater recharge, wetland reinforcement, and even direct or indirect use in the water supply network). In the developed countries, water from treated sewage is re-used principally for irrigation, while in the developing countries it is used exclusively for that purpose. Although there are no universally accepted regulations regarding reclaimed wastewater quality standards, it is, in general, considered that biologically treated sewage needs to undergo further treatment before it is to be used for unrestricted irrigation. Of particular importance are public health requirements concerning pathogenic micro-organisms. Biologically treated sewage usually needs to undergo at least $[3,4]$ :

a) Suspended particles separation, lowering the concentration of suspended solids and turbidity to a level at which subsequent disinfection will be effective, and, 
b) Disinfection, by chlorination or by UV radiation, at a dose or duration determined by the desired concentration of pathogenic organisms.

Conventional tertiary treatment schemes involve the use of the following processes (Figure 1.a):

- Coagulation (C)

- Flocculation (F)

- Settling (S)

- Sand Filtration (SF), and

- Disinfection (usually with chlorine or UV)

This "Full-treatment process" is effective, but presents two drawbacks:

a) Large doses of coagulants are required (usually $50-125 \mathrm{mg} \mathrm{I}^{-1}$ of aluminium sulphate and $0,2 \mathrm{mg} \mathrm{I}^{-1}$ of polyelectrolyte)

b) There is a need for the construction of several tanks in order to accommodate sequential treatment.

It is possible to employ smaller quantities of coagulants and to omit the settling tank stage, at least on the condition that the functioning of the preceding biological treatment stage is improved to the point where the level of suspended solids in the effluent does not exceed 45 $\mathrm{mg}^{-1}$. When this condition is met, the suggested tertiary treatment system, Direct Filtration, consists of the following stages (Figure 1.b) [5]:
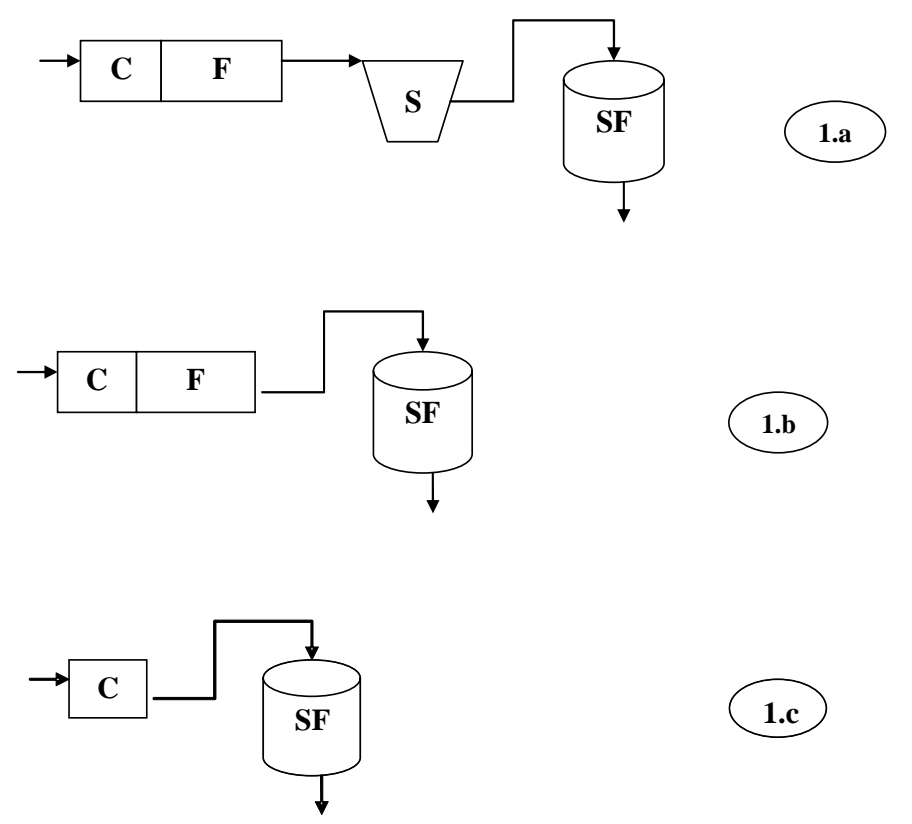

Figure 1. Various modes of tertiary physico-chemical treatment of secondary effluent

1.a. Conventional Coagulation-Sand Filtration

1.b. Direct Filtration

1.c. Contact Filtration

- Coagulation (addition of aluminium sulphate at 2-5 $\mathrm{mg} \mathrm{I}^{-1}$ and polyelectrolyte at 0,2 $\mathrm{mg} \mathrm{I}^{-1}$ )

- Flocculation

- Sand filtration

- Disinfection

The treatment sequence can be further simplified if the addition of the coagulant is done prior to filtration (Figure 1.c). In this case, flocculation takes place within the first layers of the sand filter [6]. 


\section{WASTEWATER REUSE POTENTIAL FOR CHANIA, CRETE}

The city of Chania is located on the north-western coast of the island of Crete. The municipal wastewater treatment plant receives daily around $17.000 \mathrm{~m}^{3} \mathrm{~d}^{-1}$, serving a population of around 70.000. The WTP is a conventional activated sludge facility. Mean effluent characteristics are presented in Table 1. As one can see from Table 1, the treatment plant produces a high quality effluent. This is due to the fact that the plant receives lower flowrates than the design values, as well as the proper operation of the plant. Particularly, the very low suspended solids concentration of the final effluent makes contact filtration an attractive option for wastewater reclamation.

Possible wastewater reuse may take place at the Akrotiri area located in the vicinity of the wastewater treatment plant and approximately $10 \mathrm{Km}$ from the city of Chania. The agricultural land of this area is 860 ha, while another possible application area is the campus of the Technical University of Crete (possible irrigation for 143 ha with a total of 300 ha occupied by the campus). Agricultural land, species of cultivation and irrigation water demand for the Akrotiri area are presented in Table 2. Landscape and olive tree irrigation are the main reuse potential applications for the TUC campus (Table 2). Because of these potential applications, it is appropriate that the reclaimed water quality should meet the requirements for unrestricted irrigation. This means that, apart from biological treatment, tertiary treatment is necessary.

Table 1. Mean effluent characteristics of the Chania municipal WTP (2002 data)

\begin{tabular}{lcc}
\hline Parameter & Mean value & Standard Deviation \\
\hline Flowrate, $\mathrm{m}^{3} \mathrm{~d}^{-1}$ & 17.000 & 2.600 \\
BOD, $\mathrm{mg} \mathrm{I}^{-1}$ & 6 & 4,8 \\
COD, mg l & 23 & 9,1 \\
Total Suspended Solids, $\mathrm{mg} \mathrm{I}^{-1}$ & 9 & 4,6 \\
Total Nitrogen, $\mathrm{mg} \mathrm{l}^{-1}$ & 7,8 & 2,2 \\
Total Phosphorus, $\mathrm{mg} \mathrm{l}^{-1}$ & 6,9 & 2,0 \\
\hline
\end{tabular}

In the present study, laboratory tests were carried out in order to compare the use of Coagulation-Settling and Contact Filtration, as tertiary treatment systems for the Chania WTP effluent intended for reuse. More specifically, the efficiency of these methods to remove turbidity, soluble COD and soluble phosphorus was investigated in laboratory experiments.

\section{EXPERIMENTAL MATERIALS AND METHODS \\ Wastewater}

Unchlorinated secondary effluent from the Chania WTP was used for this study. For each series of experiment 200 I of secondary effluent were carried to the lab and stored under aeration. Because the plant effluent was of good quality, mainly due to receiving a lower flowrate than the plant design capacity, the samples for experimentation were taken during times of operation when the effluent was characterized by high COD values.

In this way, the results would be more realistic to actual values, when the flowrate and subsequent the effluent characteristics would be closer to those obtained with full plant capacity.

\section{Experimental units}

Coagulation experiments were carried out with the aim of determining the required dose of

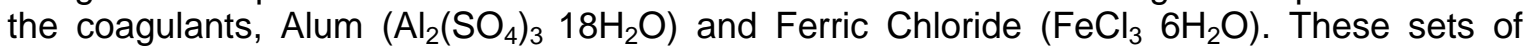
experiments were performed in a Jar Test apparatus with six 2-liter square jars. A horizontal sampling tube, $1 \mathrm{~cm}$ in diameter, had been inserted in each jar $5 \mathrm{~cm}$ from the bottom. This tube allowed sampling of water at different times during settling.

The filtration unit was a cylindrical filter with an inside diameter of $0,10 \mathrm{~m}$. The sand bed had a height of $0,75 \mathrm{~m}$. The quartz sand had a mean grain size of $0,6 \mathrm{~mm}$. Four sampling ports located at 5, 15, 35 and $70 \mathrm{~cm}$ from the sand top, respectively, allowed sampling of filtered water at different bed depths. The output of the filter was connected to a flowmeter and a 
control valve, in order to maintain a constant filter flowrate. Pressure gages were placed at 5 and $70 \mathrm{~cm}$ below the sand top in order to monitor the headloss during filtration.

Table 2. Agricultural land use and irrigation water demand for the Akrotiri area and TUC campus [7]

\begin{tabular}{ccc}
\hline Species of cultivation & Agricultural land (ha) & $\begin{array}{c}\text { Irrigation water demand from } \\
\text { April to September } \mathbf{( 1 0 0 0} \mathbf{~ m}^{\mathbf{3}} \mathbf{)}\end{array}$ \\
\hline & Akrotiri area & \\
\hline Spring potatoes & 100 & 410 \\
\hline Olive trees (for oil production) & 340 & 1120 \\
\hline Olive trees (for table olives) & 50 & 223 \\
\hline Vineyard for table grapes & 10 & 38 \\
\hline Melons & 80 & 538 \\
\hline Market vegetables & 100 & 758 \\
\hline Fodder crops & 10 & 110 \\
\hline Apricot trees & 150 & 969 \\
\hline Greenhouse tomatoes & 20 & 53 \\
\hline Total & 860 & 4222 \\
\hline & TUC area (ha) & 130 \\
\hline Olive trees & 33 & 470 \\
\hline Landscape irrigation & 110 & 600 \\
\hline Total & 143 &
\end{tabular}

\section{Experimental procedure}

For the coagulation experiments, 1 I of WTP effluent was placed into each jar. The doses used for the two coagulants (alum and ferric chloride) were set at 0,10,0,25, 0,50,0,75 and $1,0 \mathrm{mmol} \mathrm{Me}{ }^{3+} \mathrm{I}^{-1}$. For each experimental cycle, one jar received no coagulant as a control experiment. Rapid mix took place for $5 \mathrm{~min}$ at 200rpm, slow mix for $15 \mathrm{~min}$ at $45 \mathrm{rpm}$, while settling lasted for $30 \mathrm{~min}$. During settling, samples were withdrawn from the sampling ports at 0,6 and 30 min without disturbing the settling process and they were analyzed for turbidity. The level of turbidity removal by the sixth minute of settling is of interest, as this time corresponds to the overflow rates used in practice, approximately $1 \mathrm{~m}^{3} \mathrm{~m}^{-2} \mathrm{~h}^{-1}$. At the end of the settling period a sample was taken from each jar and filtered through a membrane filter with a pore size of 0,45 microns. The filtrates were analyzed for their COD and Phosphorus content.

For the sand filtration experiments, WTP effluent entered the filter from the top and exited from the bottom. The flowrate was adjusted at $60 \mathrm{I} \mathrm{h}^{-1}$, corresponding to a filtration rate of 7,6 $\mathrm{m}^{3} \mathrm{~m}^{-2} \mathrm{~h}^{-1}$ (or equivalently $127 \mathrm{I} \mathrm{m}^{-2} \mathrm{~min}^{-1}$ ), which is within the typical range of filtration rates. The coagulant was introduced just above the sand layer at a dosing level of $0,1 \mathrm{mmol} \mathrm{Me} \mathrm{M}^{3+}$ per liter of filtered effluent. Higher doses of coagulants, as tested during the coagulation experiments (Jar Tests), proved to be too high for the filtration experiments, as the filter developed a high headloss and clogged in a very short time. At the dose of $0,1 \mathrm{mmol} \mathrm{l}^{-1}$, it was possible to maintain the output of the filter at $60 \mathrm{I} \mathrm{h}^{-1}$ for over two hours, while the filter headloss did not exceed $50 \%$ of the original hydrostatic pressure. After each experimental run the filter was backwashed for 30 minutes with tap water, with the simultaneous injection of air at regular intervals.

\section{Analytical methods}

Turbidity was measured by means of a Lovibond turbidimeter. COD and Phosphorus were measured according to standard methods [8]. 


\section{RESULTS AND DISCUSSION \\ Coagulation experiments}

\section{A. Removal of turbidity}

Turbidity removal as a result of the jar tests is presented in Table 3 for Alum and Table 4 for Ferric Chloride, respectively. In these Tables, the initial turbidity of the wastewater effluent is indicated by the corresponding value at time zero without any addition of coagulant (Dose 0,0 $\mathrm{mg}^{-1}$ ). For the Alum coagulation, after the addition of the coagulant, turbidity increased as a result of hydroxide precipitation (turbidity at time 0 ). During settling, the turbidity of the supernatant decreased. However, at settling time equal to $6 \mathrm{~min}$, the supernatant turbidity was higher than the original effluent. It required longer settling times $(30 \mathrm{~min})$ and coagulant doses higher than $0,50 \mathrm{mmol} \mathrm{Me} \mathrm{m}^{3+} \mathrm{I}^{-1}$ to produce a treated effluent with turbidity less than the original one. Optimal dose was $0,50 \mathrm{mmol} \mathrm{Me}^{3+} \mathrm{I}^{-1}$, since further increase in the dose, up to $1,00 \mathrm{mmol} \mathrm{Me} \mathrm{M}^{3+} \mathrm{I}^{-1}$, slightly increased the turbidity due to the large quantities of hydroxide solids produced at high dosages. Ferric chloride showed a similar behaviour to Alum, yet the optimal dose was found $0,75 \mathrm{mmol} \mathrm{Me} \mathrm{m}^{3+} \mathrm{I}^{-1}$ (Table 4).

Table 3. Turbidity of supernatant during coagulation with Alum

\begin{tabular}{|c|c|c|c|c|c|c|c|c|c|c|c|}
\hline \multirow{3}{*}{$\begin{array}{c}\text { Settling } \\
\text { Time } \\
\text { (min) }\end{array}$} & \multicolumn{11}{|c|}{ Coagulant dose, $\mathrm{mmol} \mathrm{Me} \mathrm{Me}^{3+} \mathrm{I}^{-1}$} \\
\hline & \multicolumn{2}{|c|}{0,00} & \multicolumn{2}{|c|}{0,10} & \multicolumn{2}{|c|}{0,25} & \multicolumn{2}{|c|}{0,50} & \multicolumn{2}{|c|}{0,75} & 1,0 \\
\hline & NTU & $\%$ & NTU & $\%$ & NTU & $\%$ & NTU & $\%$ & NTU & $\%$ & NTU \% \\
\hline 0 & 3,2 & & 8,6 & & 16,3 & & 29,6 & & 45,0 & & 52,8 \\
\hline 6 & 2,0 & 37,5 & 5,3 & 36,0 & 11,1 & 31,1 & 5,8 & 80,4 & 4,9 & 89,1 & 89,6 \\
\hline 30 & 1,6 & 50,0 & 2,3 & 73,0 & 2,3 & 86,0 & 0,9 & 97,3 & 1,1 & 97,5 & 97,2 \\
\hline
\end{tabular}

Table 4. Turbidity of supernatant during coagulation with Ferric Chloride

\begin{tabular}{cccccccccccccc}
\hline \multirow{2}{*}{$\begin{array}{c}\text { Settling } \\
\text { Time } \\
(\mathbf{m i n})\end{array}$} & \multicolumn{10}{c}{$\mathbf{0 , 0 0}$} & \multicolumn{10}{c}{$\mathbf{0 , 1 0}$} & \multicolumn{10}{c}{$\mathbf{0 , 2 5}$} & $\mathbf{0 , 5 0}$ & $\mathbf{0 , 7 5}$ & & $\mathbf{1 , 0}$ \\
\cline { 2 - 14 } & NTU & $\%$ & NTU & $\%$ & NTU & $\%$ & NTU & $\%$ & NTU & $\%$ & NTU & \% \\
\hline 0 & 2,4 & & 3,9 & & 7,1 & & 14,8 & & 18,7 & & 25,8 & \\
\hline 6 & 1,8 & 25,0 & 3,3 & 15,4 & 4,5 & 36,6 & 2,6 & 82,4 & 2,6 & 86,1 & 3,9 & 84,9 \\
\hline 30 & 1,6 & 33,3 & 1,4 & 64,0 & 1,2 & 83,1 & 1,0 & 93,2 & 0,6 & 96,8 & 1,2 & 95,3 \\
\hline
\end{tabular}

\section{B. Removal of soluble COD}

The removal of soluble COD during the jar tests is presented in Figure 2 for both Alum and Ferric Chloride. As the dose increased, the removal of soluble COD increased until it reached a maximum removal rate around 50 to $60 \%$. Ferric chloride gave better results than Alum, on the average around 12 percentage removal points.

\section{Removal of phosphorus}

The removal of Phosphorus during the jar tests is presented in Figure 3 for both Alum and Ferric Chloride. At low doses (less than $0,25 \mathrm{mmol} \mathrm{Me}^{3+} \mathrm{l}^{-1}$ ) the average $\mathrm{P}$ removal was around $10-15 \%$. As the dose increased to $0,50 \mathrm{mmol} \mathrm{Me}^{3+} \mathrm{I}^{-1}$ and beyond, the removal of Phosphorus reached a maximum at $80 \%$ for Alum and $90-95 \%$ for Ferric Chloride. 


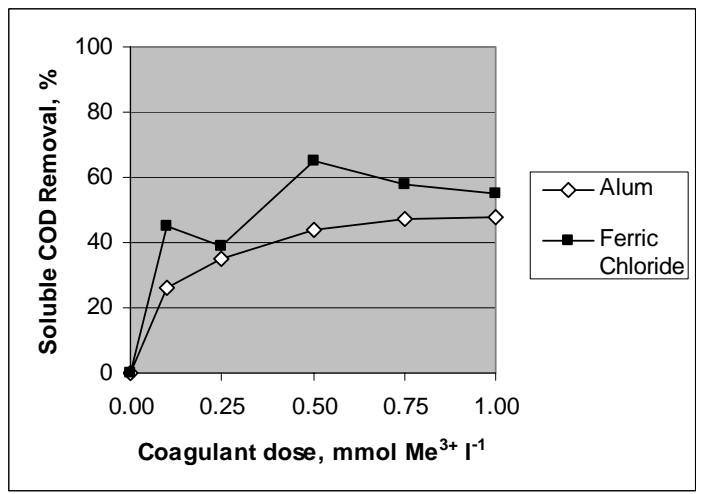

Figure 2. Soluble COD removal as a function of coagulant dose

(Initial COD concentration: During Alum experiments: $61,3 \mathrm{mg} \mathrm{l}^{-1}$; During Ferric Chloride experiments: $58,8 \mathrm{mg} \mathrm{l}^{-1}$ )

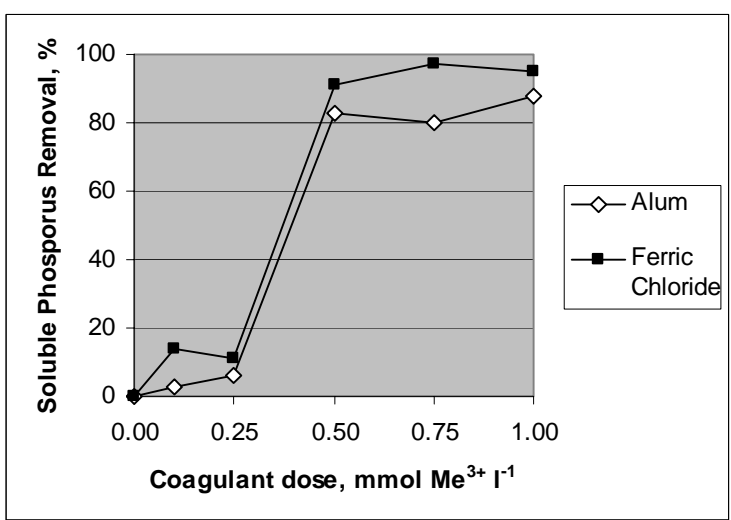

Figure 3. Soluble Phosphorus removal as a function of coagulant dose

(Initial P concentration: During Alum experiments: $3,33 \mathrm{mg} \mathrm{l}^{-1}$; During Ferric Chloride experiments: $3,59 \mathrm{mg} \mathrm{l}^{-1}$ )

\section{Contact filtration experiments}

\section{A. Removal of turbidity}

The degree of turbidity removal achieved at increasing filter depths is presented in Tables 5 for Alum and Table 6 for Ferric Chloride, respectively. For both coagulants, turbidity was removed by 50-55 \% without any significant differences due to the type of coagulant. The filter effluent was of constant quality during the filtration period $(2 \mathrm{~h})$ indicating that filter performance remained stable throughout the filtration cycle. Filtration was effective at depths of $35 \mathrm{~cm}$ or larger indicating that the suspended solids were effectively removed during the top layers of the sand filter. It should also be noted that the highest level of turbidity removal achieved during a control run without the addition of coagulant was about $35 \%$.

\section{B. Filterable $C O D$ and $P$}

Filterable COD and $P$ removals were insignificant as expected by the low coagulant doses used.

Table 5. Remaining turbidity after Contact Filtration.

Coagulant: Alum $\left(0,1 \mathrm{mmol} \mathrm{Me}^{3+} \mathrm{I}^{-1}\right)$

\begin{tabular}{cccccccc}
\hline $\begin{array}{l}\text { Filtrattion } \\
\text { Time }(\min )\end{array}$ & \multicolumn{7}{c}{ Sampling point (Filter depth in cm) } \\
\cline { 2 - 8 } & Inflow & 0 & 5 & 15 & 35 & 70 & Outflow \\
\hline 30 & 3,6 & 4,0 & 2,5 & 2,1 & 2,1 & 1,8 & 1,8 \\
\hline 60 & 3,4 & 3,6 & 2,5 & 2,0 & 1,8 & 1,9 & 1,7 \\
\hline 90 & 3,3 & 3,6 & 2,8 & 2,3 & 2,0 & 1,8 & 1,9 \\
\hline 120 & 4,2 & 4,1 & 3,0 & 2,3 & $2,0$. & 2,0 & 1,9 \\
\hline
\end{tabular}

Table 6. Remaining turbidity after Contact Filtration.

Coagulant: Ferric Chloride $\left(0,1 \mathrm{mmol} \mathrm{Me}^{3+} \mathrm{I}^{-1}\right)$

\begin{tabular}{cccccccc}
\hline $\begin{array}{c}\text { Filtration } \\
\text { Time }(\min )\end{array}$ & \multicolumn{7}{c}{ Sampling point (Filter depth in cm) } \\
\cline { 2 - 8 } & Inflow & 0 & 5 & 15 & 35 & 70 & Outflow \\
\hline 30 & 4,1 & 4,5 & 3,0 & 2,3 & 2,3 & 2,0 & 2,0 \\
\hline 60 & 4,0 & 4,6 & 3,2 & 2,3 & 2,0 & 1,9 & 1,8 \\
\hline 90 & 3,8 & 4,2 & 3,3 & 2,1 & 1,8 & 1,9 & 1,8 \\
\hline 120 & 3,9 & 4,5 & 3,8 & 2,0 & 1,9 & 1,9 & 1,9 \\
\hline
\end{tabular}




\section{Filter headloss development}

The filter headloss as a function of filtration time is presented in Figure 4 for both coagulants. During the filtration run, the increase in the filter headloss was almost linear with respect to filtration time. The headloss development appeared to have taken place during the top filter layers, since there was no significant difference in the headloss between the $5 \mathrm{~cm}$ filter depth and $70 \mathrm{~cm}$ filter depth. This indicates that most of the suspended particles were deposited within the top layers of the sand filter. However, there was a marked difference in headloss development when the two coagulants were used. The use of Alum produced a lower rate of headloss development, while, when Ferric Chloride was used, headloss development was twice as high. Since there were no real differences in the performance of the two coagulants regarding turbidity removal during filtration, then it appears that limitations in the developed headloss may be the limiting factor in a full-scale contact filtration of the WTP effluent.

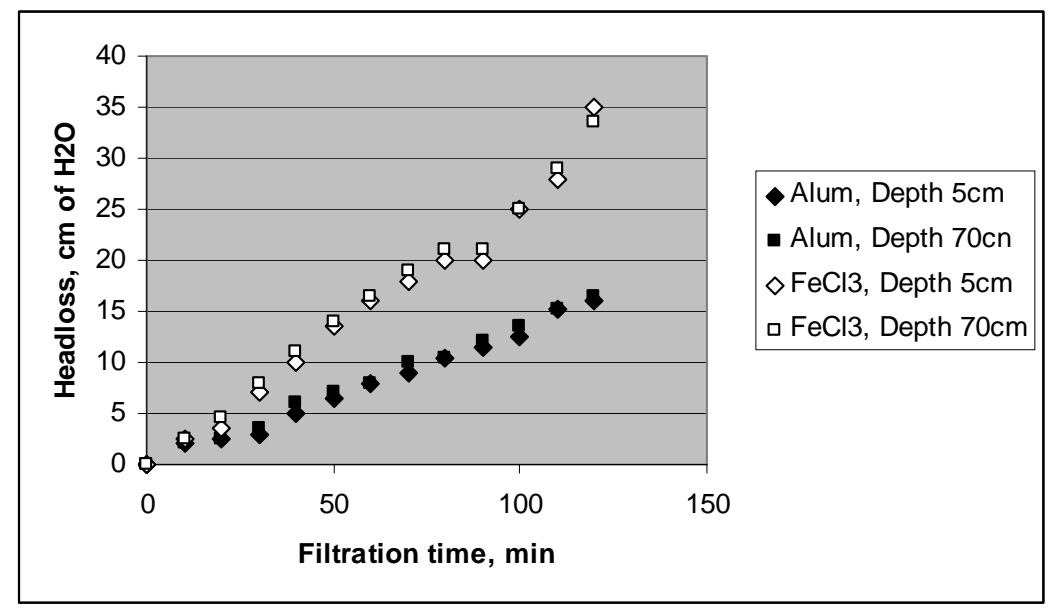

Figure 4. Filter headloss as a function of filtration time (Coagulant dose: 0,1 mmol $\mathrm{Me}^{3+} \mathrm{I}^{-1}$ )

From these laboratory tests described above, one may conclude that both conventional coagulation, as well as contact filtration can be employed for tertiary treatment of the secondary effluent from the Chania WTP, if intended for reuse. The conventional treatment will use high concentrations of coagulants, it will produce larger quantities of sludge, but at the same time it will achieve moderate removals of COD and high removals of phosphorus. However, since the WTP effluent is in general low in suspended solid (usually less than 30 $\mathrm{mg}^{-1}$ ), contact filtration is also a viable option, since the produced filtered effluent could have a turbidity level of less than 2 NTU. The existence of Phosphorus in the tertiary effluent may also be desired, if the reclaimed wastewater is intended for irrigation, therefore reducing the demand for fertilizers.

\section{CONCLUSIONS}

Based on the results presented above, the following conclusions can be drawn:

- Removal of turbidity from the Chania secondary effluent by Alum and Ferric coagulation and subsequent settling was around $80 \%$, with coagulant doses greater than $0,50 \mathrm{mmol} \mathrm{Me}^{3+} \mathrm{I}^{-1}$. At these coagulant doses, soluble COD was also removed by about $50 \%$, while soluble Phosphorus by $80-95 \%$. Higher coagulant doses resulted in only slightly further removals.

- Between the two coagulants used, Ferric Chloride demonstrated better efficiency achieving around 10 to 15 removal percentage points higher than Alum for soluble COD and soluble phosphorus.

- The use of coagulants in the contact filtration experiments resulted in turbidity removals by $50-55 \%$ with a coagulant dosage of $0,1 \mathrm{mmol} \mathrm{Me} \mathrm{m}^{3+} \mathrm{I}^{-1}$. During control experiments (no coagulant added) turbidity removal was around $35 \%$. Soluble COD and soluble Phosphorus removals were insignificant due to the low coagulant dose. Both coagulants showed similar removal efficiencies. 
- A sand layer of $35 \mathrm{~cm}$ was shown to be adequate for the removal of turbidity. Increasing the thickness beyond this value produced only a minimal improvement in the quality of the reclaimed water.

- The smallest filter headlosses during two hours of continuous filtration were observed with the use of Alum. Filter headloss with the use of ferric chloride was twice as large. There was no difference between the headloss at a filter depth of $5 \mathrm{~cm}$ as compared to the headloss at a depth of $70 \mathrm{~cm}$, as the most of suspended and colloidal solids were deposited within the first layers of the sand filter.

\section{ACKNOWLEDGEMENTS}

This work was financially supported by the Chania Water Supply and Sanitation Municipal Company.

\section{REFERENCES}

1. Crook J. (1991), Quality criteria for reclaimed water, Water Science and Technology, 24(9), 109-121.

2. Levine A. and Shiasano T. (2004), Recovering sustainable water from wastewater, Environmental Science \& Technology, 38, 201a-208a.

3. Asano, T. et al. (1992), Evolution of tertiary treatment requirements in California", Water Environment and Technology, 2, 36-41.

4. Adin A. and Asano T. (1998), The role of physical-chemical treatment in wastewater reclamation and reuse, Water Science \& Technology, 37(10), 79-90.

5. Logsdon, G.S., Neden, D. Gr., Ferguson, A.M.D. and La Bonde, S.D., (1993), Testing direct filtration for the treatment of high-turbidity water, Journal of American Water Works Association, 85, 39-46.

6. Boller, M.A. (1984), Chemical optimization of tertiary contact filters", Journal of Environmental Engineering Division, ASCE, 110, 263-277.

7. Western Crete Development Organisation (O.A.D.Y.K.) (1988), Effective use of water resources in Western Crete - Irrigation works in the Akrotiri area, Agrotechnical - Agroeconomic study.

8. Greenberg, A.E., Clesceri, L.S. and Eaton A.D. (Eds.) (1992) Standard Methods for the Examination of Water and Wastewater, APHA AWWA, WEF, 18th ed. 